\title{
ANÁLISE COMPARATIVA DA PERMEABILIDADE DA PAVIMENTAÇÃO INTERTRAVADA DE CONCRETO, UTILIZANDO AGREGADO GRAÚDO E AGREGADO MIÚDO
}

\section{ARTIGO ORIGINAL}

SEGUNDO, Demerval Martins dos Santos ${ }^{1}$, SOUSA, Hyago Sodré ${ }^{2}$, LOPES, Hígor Jônathas Sena Dias ${ }^{3}$, ARAUJO, Wendel Melo Prudêncio de ${ }^{4}$, GOMES, Renan Maycon Mendes 5

SEGUNDO, Demerval Martins dos Santos. Et al. Análise comparativa da permeabilidade da pavimentação intertravada de concreto, utilizando agregado graúdo e agregado miúdo. Revista Científica Multidisciplinar Núcleo do Conhecimento. Ano. 06, Ed. 12, Vol. 04, pp. 86-101. Dezembro de 2021. ISSN: 24480959, Link de acesso: https://www.nucleodoconhecimento.com.br/engenhariacivil/pavimentacao-intertravada

\section{RESUMO}

Os alagamentos e as inundações podem gerar vários transtornos, como impedimento do trânsito de veículos e transeuntes, progresso de ação erosiva de encostas, poluição de águas pluviais por mistura de lixo inserido de forma irregular no arruamento, entre outros, que são maximizados, devido aos processos de urbanização das grandes cidades, que intensificam a impermeabilização do solo, fator que aumenta o escoamento superficial. Portanto, a problemática deste artigo está em reduzir o excesso de água pluvial que provoca alagamentos e inundações, para

\footnotetext{
1 Graduado em Engenharia Civil.

2 Graduado em Engenharia Civil.

${ }^{3}$ Graduado em Engenharia Civil.

${ }^{4}$ Orientador.

${ }^{5}$ Orientador.
} 
melhoria da qualidade do recurso hídrico e da mobilidade urbana. O objetivo desta pesquisa se destina em fazer a análise comparativa da permeabilidade da pavimentação intertravada de concreto, utilizando agregado graúdo e miúdo. Para o desenvolvimento deste trabalho, elaboraram-se dois módulos experimentais que simularam o seu estado inicial de aplicação, sendo que um adotou o material com características granulométricas sugeridas pela Associação Brasileira de Normas Técnicas - ABNT -, e outro adotando agregado miúdo, dos quais ambos foram utilizados nas camadas de assentamento e de rejunte, em que os ensaios seguiram as diretrizes normativas descritas. Foram obtidos valores de $5,79 \times 10^{-5} \mathrm{~m} / \mathrm{s}$ a $3,23 \mathrm{x}$ $10^{-5} \mathrm{~m} / \mathrm{s}$ no ensaio de permeabilidade no módulo experimental de piso intertravado em que foi utilizado a areia nestas camadas; e valores entre $3,83 \times 10^{-3} \mathrm{~m} / \mathrm{s}$ a 2,86 $\mathrm{x}$ $10^{-3} \mathrm{~m} / \mathrm{s}$ no mesmo teste, utilizando a brita com granulometria indicada na norma na mesma finalidade, indicando que houve melhores resultados em que foi utilizado agregado com maior granulometria, atendendo o valor mínimo de $10^{-3} \mathrm{~m} / \mathrm{s}$ exigido pela norma. Os módulos experimentais de piso intertravado conseguiram alcançar o objetivo definido, constatando-se que apenas o modelo que seguiu as características indicadas pela norma atendeu o critério de seu coeficiente de permeabilidade, enquanto àquele que foi utilizado o agregado miúdo atingiu resultados muito inferiores ao exigido por ela, podendo indicar que esta norma possui bastante rigidez no quesito de desempenho de permeabilidade. Além disso, é possível constatar a diminuição do coeficiente de permeabilidade com o decorrer dos dias de ensaio, provavelmente ocasionado pela compactação dos agregados durante o período de testes.

Palavras-chave: drenagem urbana, pavimentos intertravados de concreto, módulos experimentais.

\section{INTRODUÇÃO}

Derivado de uma urbanização não planejada e não uniforme, com baixa infraestrutura e moradias locadas em áreas de risco, as inundações urbanas, que são eventos naturais, estão sendo cada vez mais recorrentes, desde as grandes metrópoles às cidades interioranas. Além do mais, a existência de áreas urbanas mais valorizadas 
em relação a outras, sem assistência adequada de infraestrutura e serviços públicos, tem como consequência a vulnerabilidade de parcelas da população a desastres naturais, segregando-as também ao acesso a bens sociais (GUIMARÃES, 2018).

Contaminação por doenças infectocontagiosas, suspensão das atividades econômicas existentes na região afetada, danos materiais e mortes são algumas das consequências das inundações, aliados ao sistema irregular de esgotamento sanitário, o acúmulo de lixo nas galerias e arruamentos com ineficiente capacidade de permitir a infiltração adequada da água (OLIVEIRA, 2017).

Os pisos intertravados de concreto permitem a diminuição do escoamento superficial através das suas juntas de percolação, elevando a superfície permeável dos centros urbanos, sendo utilizados em estacionamentos, passagem de transeuntes, e até mesmo para o tráfego leve de veículos. Vale ressaltar que o volume precipitado infiltra no pavimento, sendo filtrado pela camada de base do mesmo, e armazenada pelas camadas de base e sub-base (MARCHIONI, 2011).

Então, no sentido de desenvolver práticas sustentáveis que visem a melhoria da qualidade do recurso hídrico e da mobilidade urbana, a análise da permeabilidade da pavimentação intertravada de concreto deve propor a melhoria de sua eficiência, podendo abranger a linha de pesquisa para diferentes tipos de pisos permeáveis de diferentes locais que utilizam este tipo de pavimento, para a diminuição do escoamento superficial, que gera problemas de inundações, principalmente nos centros urbanos.

A problemática deste artigo está idealizada em como minimizar o transtorno que a água da chuva ocasiona na infraestrutura urbana, com o propósito em melhorar da qualidade do recurso hídrico e da mobilidade urbana.

Logo, o objetivo geral desta pesquisa está voltado a analisar a permeabilidade da pavimentação intertravada de concreto, utilizando agregado graúdo e miúdo, cujos objetivos específicos são de elaborar dois módulos experimentais que simulem seu 
estado inicial de aplicação, realizar de ensaios de permeabilidade nestes módulos e avaliar o coeficiente de permeabilidade deles.

\section{MÉTODOS}

Nesta pesquisa foram elaborados dois modelos de pavimentação intertravada, sendo que o primeiro simulou a pavimentação da Instituição de Ensino Superior, como exemplificação de ensaio (Figura 1), e o segundo a pavimentação com características descritas pela NBR 16416 (ABNT, 2015), conforme descritas nas Tabelas 1 a 4.

Figura 1: Modelo de piso intertravado com camada de assentamento em areia

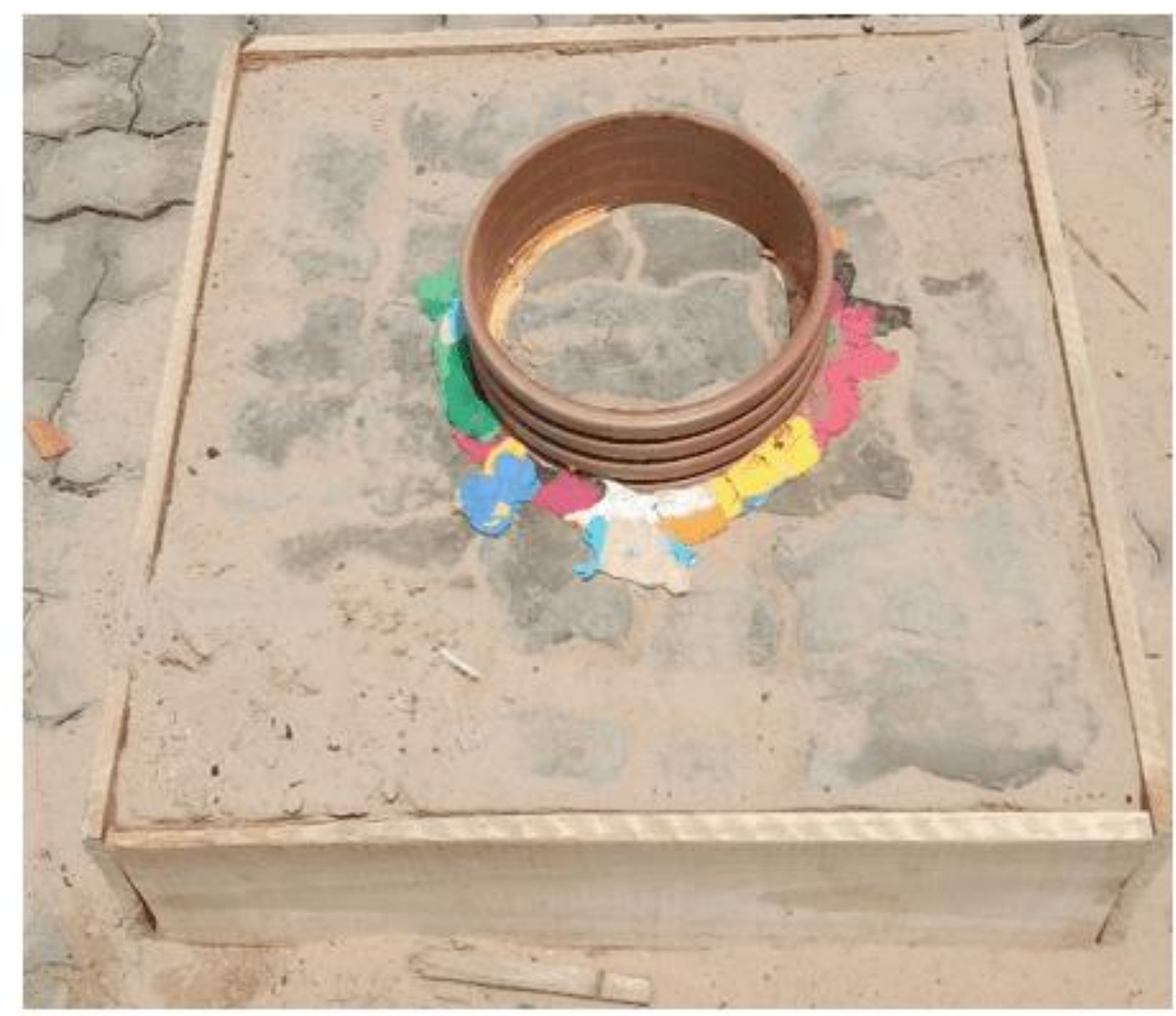

Fonte: (AUTOR, 2018)

A Imagem acima mostra o módulo experimental formado por agregado miúdo nas camadas de assentamento e de rejunte, com o cilindro de ensaio vedado com massa de modelar. 
Tabela 1: Especificações para o material de rejuntamento

\begin{tabular}{|l|l|l|}
\hline Propriedade & Método & Especificação \\
\hline Abrasão "Los Angeles" & $\begin{array}{l}\text { ABNT NBR } \\
\text { NM } 51\end{array}$ & $<40 \%$ \\
\hline Índice de vazios & $\begin{array}{l}\text { ABNT NBR } \\
\text { NM } 45\end{array}$ & $\geq 32 \%$ \\
\hline Material passante na peneira com & ABNT NBR & $\leq 2 \%$ \\
abertura de malha de $0,075 \mathrm{~mm}$ & NM 46 & \\
\hline $\begin{array}{l}\text { Dimensão máxima característica } \\
\text { (Dmáx) }\end{array}$ & ABNT NBR & $\leq 1 / 3$ da menor largura da \\
\hline
\end{tabular}

Fonte: $(A B N T, 2015)$

A Tabela acima mostra a descrição das características que a NBR 16416 (ABNT, 2015) exige para o material que deve ser utilizado na camada de rejuntamento.

Tabela 2: Distribuição granulométrica recomendada para o material de rejuntamento

\begin{tabular}{|l|l|}
\hline Peneira com abertura de malha & Porcentagem retida em massa \% \\
\hline $12,5 \mathrm{~mm}$ & 0 \\
\hline $9,5 \mathrm{~mm}$ & 0 a 15 \\
\hline $4,75 \mathrm{~mm}$ & 70 a 90 \\
\hline $2,36 \mathrm{~mm}$ & 90 a 100 \\
\hline $1,16 \mathrm{~mm}$ & 95 a 100 \\
\hline
\end{tabular}

Fonte: (ABNT, 2015)

A Tabela acima mostra a recomendação da NBR 16416 (ABNT, 2015) faz em relação à curva granulométrica do material utilizado na camada de rejuntamento. 
Tabela 3: Especificações para o material da camada de assentamento

\begin{tabular}{|l|ll|l|}
\hline Propriedade & Método & Especificação \\
\hline Abrasão "Los Angeles" & ABNT & NBR & $<40 \%$ \\
& NM 51 & & \\
\hline Índice de vazios & ABNT & NBR & $\geq 32 \%$ \\
& NM 45 & & \\
\hline Material passante na peneira com abertura de & ABNT & NBR & $\leq 2 \%$ \\
malha de 0,075 mm & NM 46 & & \\
\hline Dimensão máxima característica (Dmáx) & ABNT & NBR & $9,5 \mathrm{~mm}$ \\
& 7212 & & \\
\hline
\end{tabular}

Fonte: (ABNT, 2015)

A Tabela acima mostra a descrição das características que a NBR 16416 (ABNT, 2015) exige para a camada de assentamento dos pisos intertravados.

Tabela 4: Distribuição granulométrica recomendada para o material de assentamento

\begin{tabular}{|l|l|}
\hline Peneira com abertura de malha & Porcentagem retida em massa \% \\
\hline $12,5 \mathrm{~mm}$ & 0 \\
\hline $9,5 \mathrm{~mm}$ & 0 a 15 \\
\hline $4,75 \mathrm{~mm}$ & 70 a 90 \\
\hline $2,36 \mathrm{~mm}$ & 90 a 100 \\
\hline $1,16 \mathrm{~mm}$ & 95 a 100 \\
\hline
\end{tabular}

Fonte: (ABNT, 2015)

A Tabela acima mostra a recomendação da NBR 16416 (ABNT, 2015), para a distribuição granulométrica do material de assentamento dos pavimentos intertravados. 
A norma americana ASTM C1701 (2009): Standard Test Method for Infiltration Rate of In Place Pervious Concrete descreve os critérios e procedimentos para este teste, e segundo Ono; Balbo e Cargnin (2017), a NBR 16416 (ABNT, 2015) incorporou a americana para este ensaio.

Para a execução dos ensaios, foram necessários os seguintes materiais:

- Cilindro rígido e resistente a água, com diâmetro interno de (300 \pm 10$) \mathrm{mm}$;

- Massa de modelar;

- Balde capaz de armazenar pelo menos 20 litros;

- Proveta;

- Cronômetro;

- Água.

Na superfície externa dos módulos experimentais, montou-se o sistema formado pelo cilindro, vedado com massa de calafetar, para que o volume de água que seria utilizado não escapasse do cilindro em questão. Contudo, de acordo com a norma em análise, especifica-se a utilização da massa de calafetar para os ensaios, porém, para que houvesse economia de material de vedação, e para sua reutilização, substituiuse a massa especificada em norma por massa de modelar.

Definido de pré-molhagem, inseriu-se 3,6 litros de água no sistema corretamente vedado, cronometrando-se o intervalo de tempo referente entre o início do despejo do líquido no cilindro de ensaio e a infiltração total deste (Figura 2). Caso este intervalo fosse inferior a 30 segundos, o volume utilizado para o ensaio definitivo seria de 18 litros; caso contrário, novamente 3,6 litros. 
Figura 2: Método de ensaio NBR 16416 (ABNT, 2015)

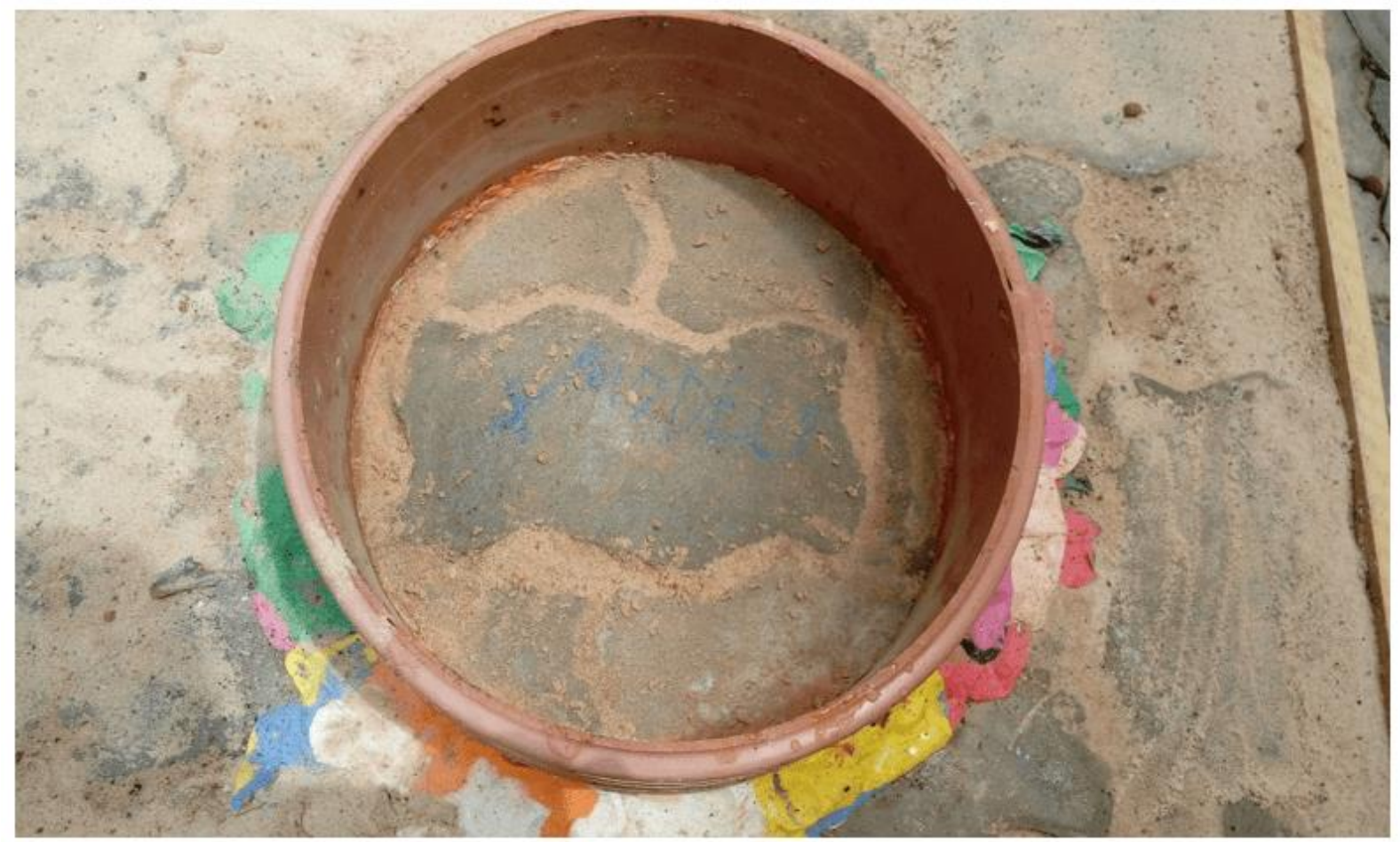

Fonte: (AUTOR, 2018)

A Imagem acima mostra o módulo experimental com areia após o procedimento de ensaio normatizado de pré-molhagem.

Após a definição do volume de água necessário para o ensaio definitivo, inseriu-se este volume, no intervalo de tempo máximo de 2 minutos após a pré-molhagem. Foi novamente cronometrado o intervalo de tempo referente entre o início do despejo do líquido no cilindro de ensaio e a infiltração total deste.

Vale ressaltar que a NBR 16416 (ABNT, 2015) faz algumas observações que são importantes para o ensaio em análise, como não aceitar a execução de mais de 02 testes no mesmo dia; o volume de água para a pré-molhagem e no ensaio definitivo devem ser inseridos com uniformidade, destacando-se que altura da lâmina d'água deve estar entre duas demarcações internas pré-estabelecidas, de 10 e $15 \mathrm{~mm}$ em relação a borda inferior do cilindro; e deve prevalecer o local mais baixo do cilindro para a demarcação da altura da lâmina d'água, se houver inclinação. 
De acordo com a NBR 16416 (ABNT, 2015), deve-se utilizar a Equação 1 para cálculo do coeficiente de permeabilidade.

$$
\mathrm{k}=\frac{\mathrm{C} \times \mathrm{m}}{\left(\mathrm{d}^{2} \times \mathrm{t}\right)}
$$

(1)

sendo que:

- $\quad k=$ Coeficiente de permeabilidade $(\mathrm{mm} / \mathrm{h})$;

- $\quad m=$ Massa de água utilizada $(\mathrm{kg})$;

- $\quad \mathrm{d}=$ Diâmetro interno do cilindro (mm);

- $\quad t$ = Tempo cronometrado para a infiltração total da água (s);

- $\quad \mathrm{C}=$ Constante, fator de conversão de unidades, igual a 4583666000.

O resultado foi comparado com os valores da Tabela 5, que caracteriza o grau de permeabilidade do solo.

Tabela 5: Valores típicos de coeficiente de permeabilidade

\begin{tabular}{|l|l|l|}
\hline \multicolumn{2}{|l|}{ Coeficiente de Permeabilidade do solo (k) } & \multicolumn{2}{l|}{ Grau de permeabilidade } \\
\hline $\mathrm{m} / \mathrm{s}$ & $\mathrm{mm} / \mathrm{h}$ & do solo \\
\hline$>10^{-3}$ & $>3600$ & alta \\
\hline $10^{-3} \mathrm{a} \mathbf{1 0}^{-5}$ & $3600 \mathrm{a}>36$ & média \\
\hline $10^{-5} \mathrm{a} 10^{-7}$ & $36 \mathrm{a}>0,36$ & baixa \\
\hline $10^{-7} \mathrm{a} 10^{-9}$ & $0,36 \mathrm{a} 0,0036$ & muito baixa \\
\hline$<10^{-9}$ & $<0,0036$ & praticamente impermeável \\
\hline
\end{tabular}

Fonte: (ABNT, 2015) 
A Tabela acima mostra os valores típicos dos coeficientes de permeabilidade em função do grau de permeabilidade do solo, de acordo com a NBR 16416 (ABNT, 2015).

Apoiado em uma superfície regular e plana, foi montado uma caixa de madeira, com área de 0,56 $\mathrm{m}^{2}$, sendo que suas dimensões são de $0,75 \times 0,75 \mathrm{~m}$, e altura de 0,20 $\mathrm{m}$, e com duas aberturas (superior e inferior), pois $0,04 \mathrm{~m}$ foram destinados a camada de base; para a camada de assentamento em 0,08 m; assim como 0,08 m para o revestimento, dimensionado para tráfego leve, conforme a NBR 16416 (ABNT, 2015); adequando-se a área mínima de $0,50 \mathrm{~m}^{2}$, de acordo com a mesma norma. Depois disso, foi lançada a camada permeável, compactando-se adequadamente; logo após isso, foi inserido a camada de assentamento, também devidamente compactada; em seguida foram colocados os blocos pré-fabricados de concreto. No final, foi aplicado a camada de rejuntamento. Os dois modelos seguiram esta metodologia descrita, porém o primeiro possuiu a camada de assentamento e de rejunte com características granulométricas semelhantes a que a Instituição utiliza; e o segundo com granulometria descrita na norma em análise (Figura 3).

Figura 3: Modelo de piso intertravado com camada de assentamento e rejunte em brita

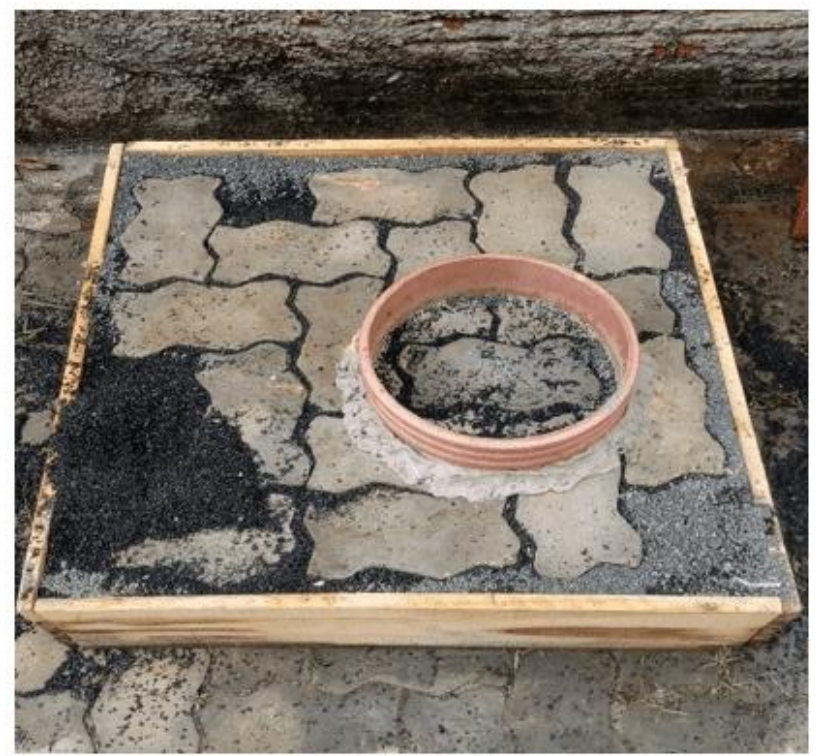

Fonte: (AUTOR, 2018)

Disponível em: https://www.nucleodoconhecimento.com.br/engenharia-civil/pavimentacao- 
A Imagem acima mostra o módulo experimental formado por agregado graúdo (brita) nas camadas de assentamento e de rejunte, com o cilindro de ensaio vedado com massa de modelar, após o procedimento normatizado de pré-molhagem.

\section{RESULTADOS E DISCUSSÕES}

Para a elaboração do modelo de pavimento intertravado de concreto, utilizando areia como material para a camada de assentamento e de rejunte, a curva granulométrica dele está apresentada na Figura 4.

Figura 4: Curva granulométrica da areia utilizada como camada de assentamento

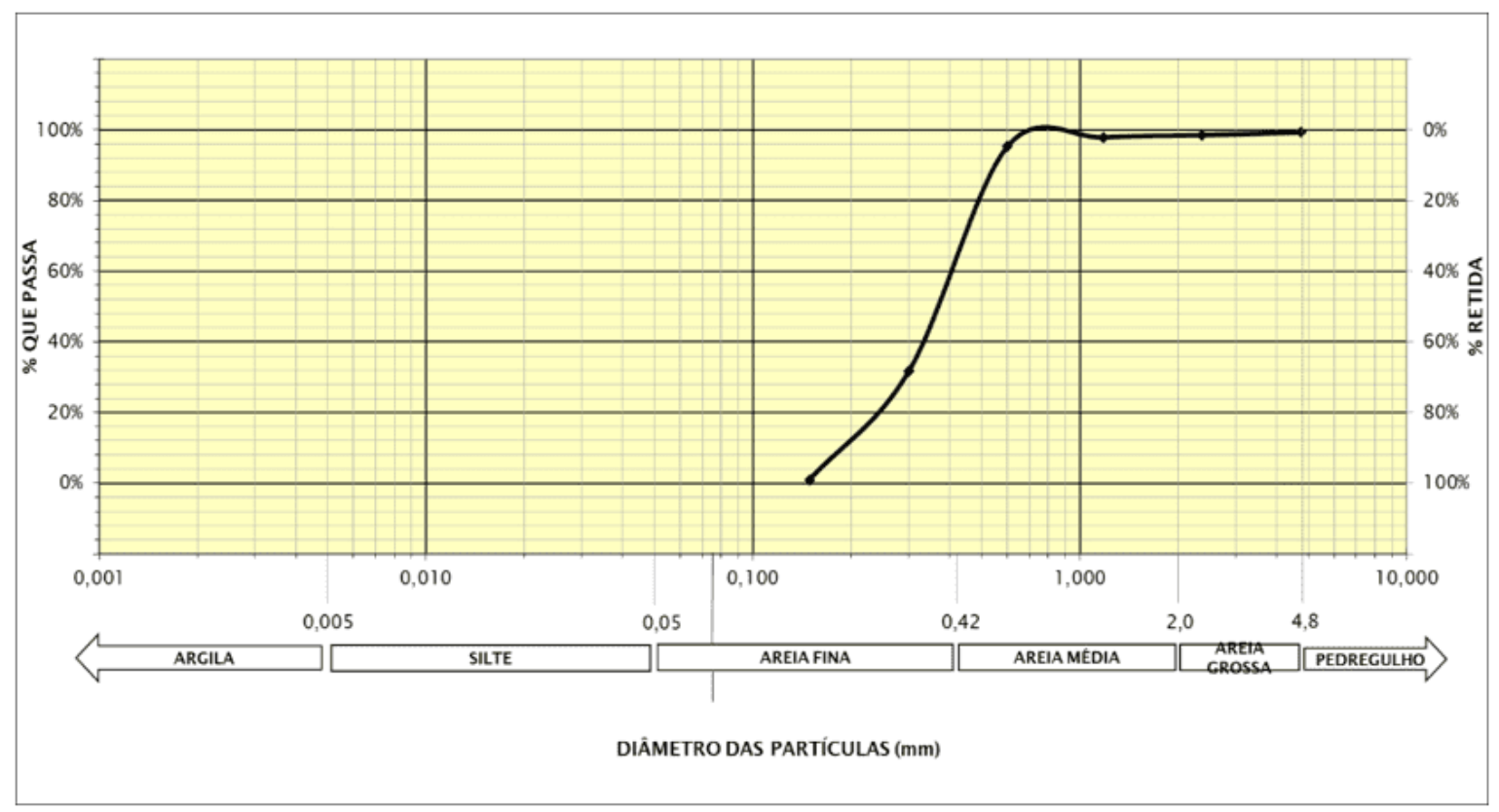

Fonte: (AUTOR, 2018)

A Imagem acima mostra o resultado do ensaio de granulometria do material utilizado pela Instituição de Ensino Superior, nas camadas de assentamento e de rejunte, que foi utilizado essa curva granulométrica para definição do módulo experimental com areia. 
$\mathrm{Na}$ Figura 5 mostra o resultado do ensaio de permeabilidade no modelo de pavimento intertravado com areia como material de camada de assentamento e de rejunte, sendo que em todos os testes foram utilizados 3,6 litros de água.

Figura 5: Resultado do ensaio em modelo de piso intertravado com areia

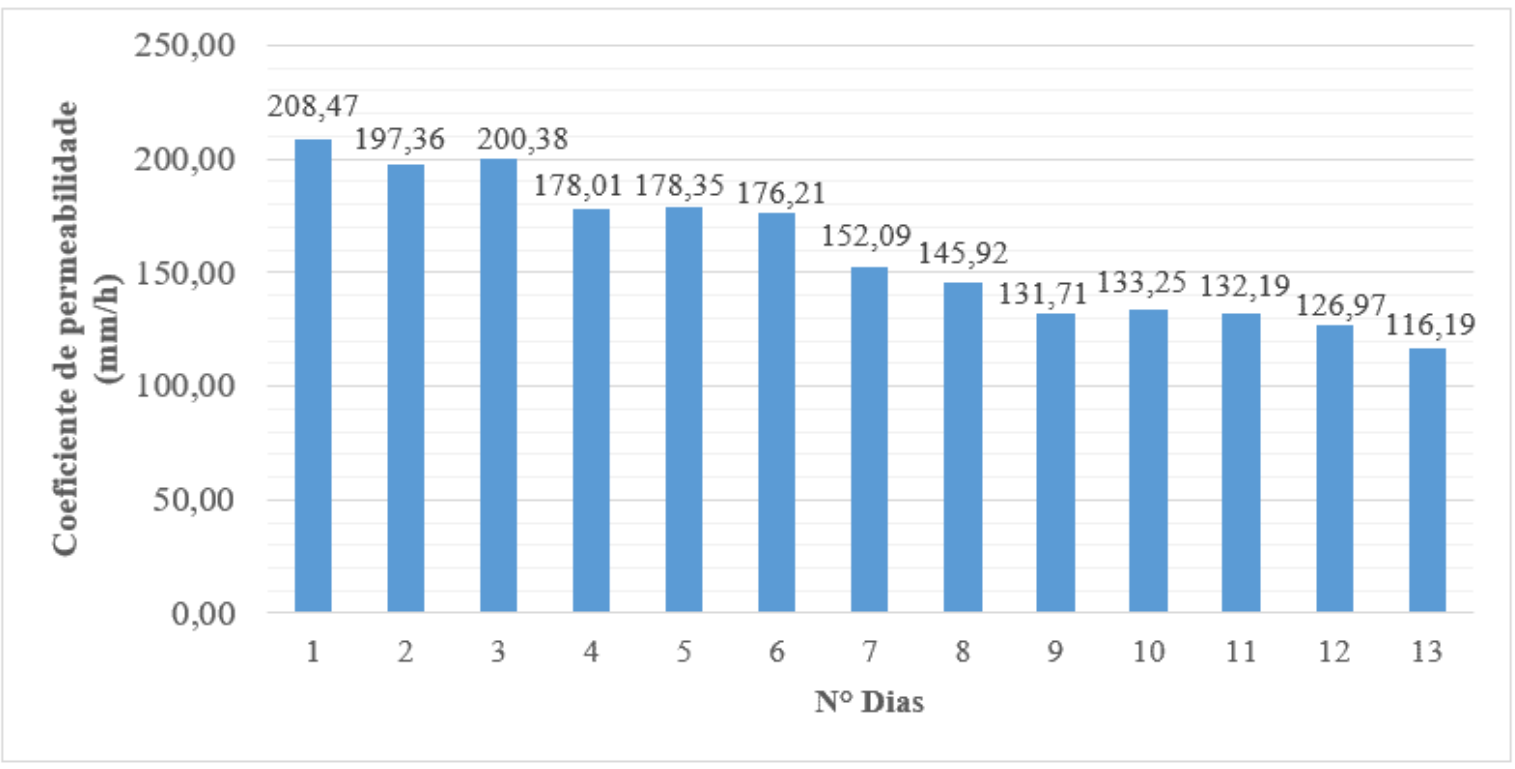

Fonte: (AUTOR, 2018)

A Imagem acima mostra o resultado referente ao modelo de piso intertravado com areia, constatando-se que com o decorrer do tempo, isto é, da quantidade de dias de ensaio, houve o acréscimo de intervalo de tempo, ocasionando, por sua vez, a diminuição do coeficiente de permeabilidade. Além disso, percebe-se que os primeiros valores de coeficiente de permeabilidade estão muito abaixo que a NBR 16416 (ABNT, 2015) estabelece para pavimentos intertravados recém-construídos: da expectativa de $3600 \mathrm{~mm} / \mathrm{h}$ da norma vigente $\left(10^{-3} \mathrm{~m} / \mathrm{s}\right)$, para valores reais de 208,47 $\mathrm{mm} / \mathrm{h}$ e $197,36 \mathrm{~mm} / \mathrm{h}\left(5,79 \times 10^{-5} \mathrm{~m} / \mathrm{s}\right.$ e $5,48 \times 10^{-5} \mathrm{~m} / \mathrm{s}$, respectivamente) obtidos no ensaio de permeabilidade. Este resultado pode ter ocorrido por causa da compactação da areia durante o período de uso para o controle de escoamento superficial (Figura 6), além de se constatar que este material pode não ser o mais adequado para a camada drenante de assentamento e rejuntamento do pavimento intertravado por sua distribuição granulométrica, conforme parâmetros exigidos na norma vigente. 
Figura 6 - Modelo de pavimento intertravado de concreto com areia

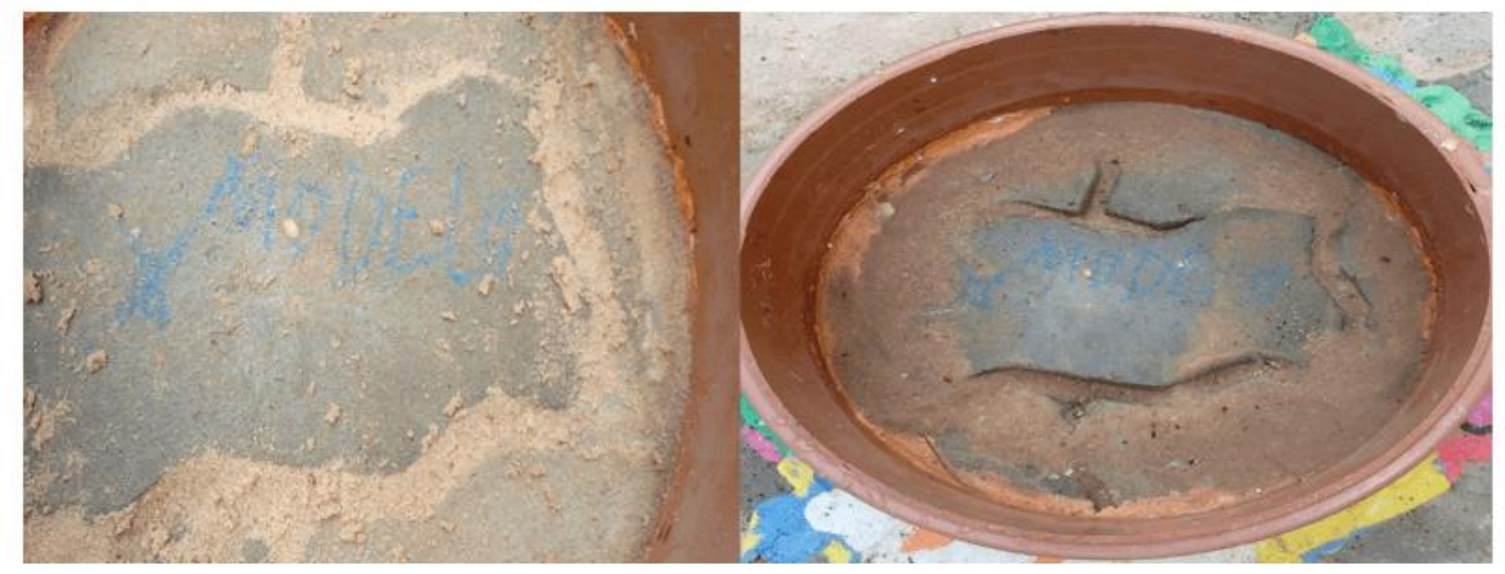

Fonte: (AUTOR, 2018)

A Imagem acima mostra modelo de pavimento intertravado antes e após o procedimento normatizado de ensaio de aplicação de água, respectivamente, verificando-se a movimentação do material de rejunte.

O material utilizado na camada de assentamento do modelo de pavimento intertravado de concreto com brita seguiu a distribuição granulométrica exposta na Figura 7, sendo que na NBR 16416 (ABNT, 2015) sugere uma faixa granulométrica para esta camada, onde a linha azul descreve a granulometria máxima e a vermelha a granulometria mínima para o material em análise. 
Figura 7: Curva granulométrica da brita utilizada como camada de assentamento

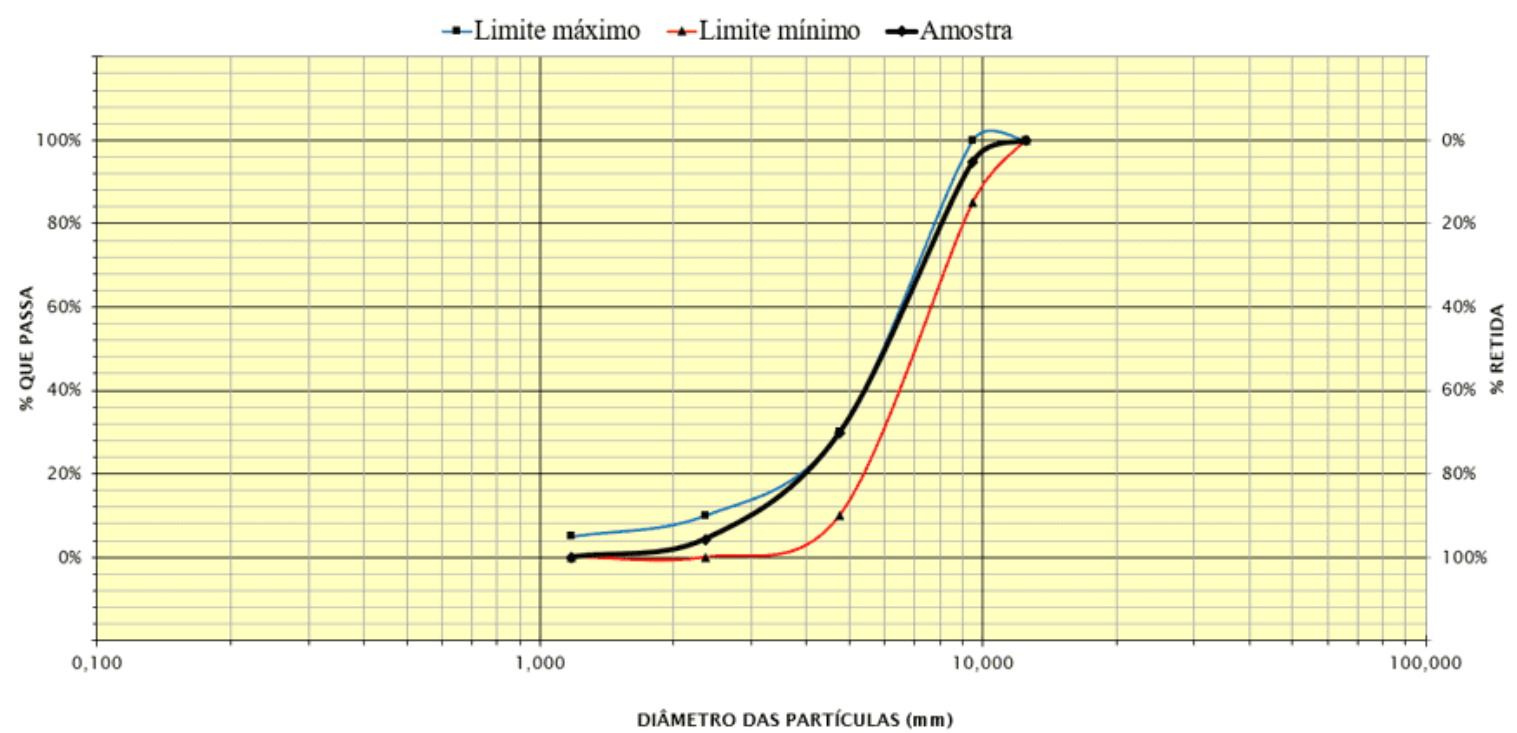

Fonte: (AUTOR, 2018)

A Imagem acima mostra o resultado do ensaio de granulometria do material indicado pela NBR 16416 (2015), nas camadas de assentamento e de rejunte, que foi utilizado essa curva granulométrica para definição do módulo experimental com brita, respeitando-se os limites máximo (linha azul) e mínimo (linha vermelha) normativos.

Os valores referentes ao resultado do ensaio de determinação do coeficiente de permeabilidade do modelo de pavimento intertravado de concreto, utilizando a brita como camada de assentamento, estão representados na Figura 8. Estes foram obtidos utilizando 18 litros de água nos testes, pois todos possuíram intervalo de tempo inferior a 30 segundos na pré-molhagem. 
Figura 8: Resultado do ensaio em modelo de piso intertravado com brita

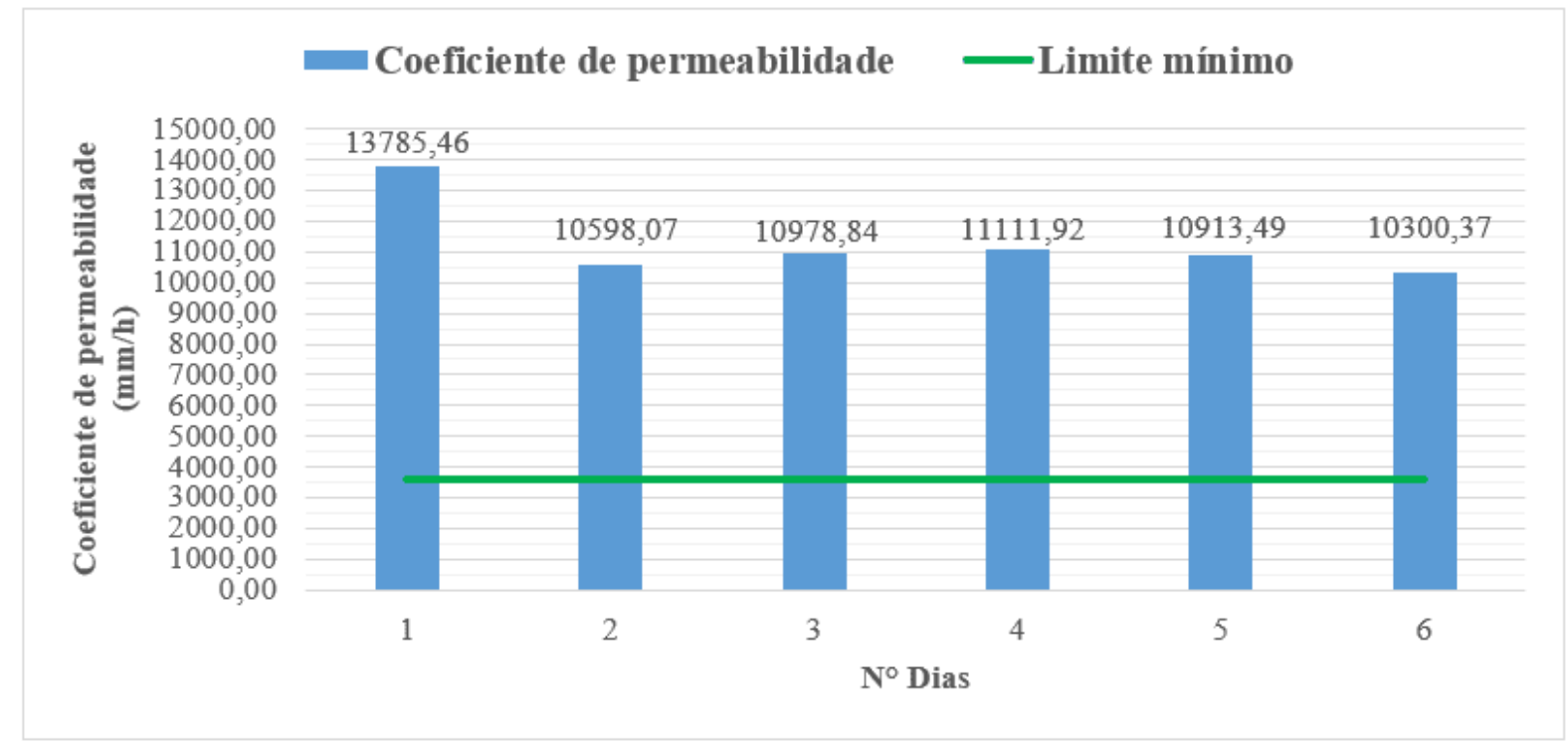

Fonte: (AUTOR, 2018)

A Imagem acima mostra o resultado referente ao modelo de pavimento intertravado com brita, sendo que se pode constatar que ele possui alto grau de permeabilidade, muito superior ao limite mínimo estabelecido pela NBR 16416 (ABNT, 2015), de 10³ $\mathrm{m} / \mathrm{s}$ (3600 mm/h), podendo ser adequado o uso da brita em sua camada de assentamento e de rejunte, considerando a distribuição granulométrica preestabelecida, para sua função drenante, segundo os parâmetros da norma analisada. Foi constatado também que os valores do coeficiente de permeabilidade se mantiveram constantes ao decorrer dos dias de ensaio, do qual o primeiro dia de testes apresentou o melhor resultado, de $13785,46 \mathrm{~mm} / \mathrm{h}$, ou $3,83 \times 10^{-3} \mathrm{~m} / \mathrm{s}$. Estes resultados podem ter sido alcançados por conta da granulometria mais aberta do material, em comparação à areia utilizada no primeiro modelo de pavimento intertravado de concreto, tanto na camada de assentamento, quanto de rejuntamento. 


\section{CONCLUSÃO}

Para os ensaios referentes ao cálculo do coeficiente de permeabilidade, foi atingido o objetivo da massa de modelar, com sua função de vedar o sistema analisado em todos os dias de ensaio, suprindo adequadamente a massa de calafetar.

$\mathrm{Na}$ elaboração dos módulos experimentais de pavimentos intertravados, conseguiuse atingir ao objetivo proposto. Contudo, o valor que a norma analisada exige para o coeficiente tanto após a execução do pavimento, quanto após a prática da manutenção, podem ser considerados muito elevados devido aos valores alcançados do módulo experimental de piso intertravado com areia na camada de assentamento e rejuntamento nos seus primeiros dias de execução serem muito inferiores aos dos valores da norma. Além disso, deve-se ressalvar que esta pesquisa está voltada apenas para a análise do desempenho de permeabilidade do piso intertravado, não sendo analisados os seus desempenhos mecânicos (adequação ao tráfego, por exemplo).

\section{REFERÊNCIAS}

ASSOCIAÇÃO BRASILEIRA DE NORMAS TÉCNICAS. NBR 16416: pavimentos permeáveis de concreto -Requisitos e procedimentos. Rio de Janeiro, 2015.

ASTM - AMERICAN SOCIETY FOR TESTING AND MATERIALS. ASTM C1701 I C1701M-09: Standard Test Methods for Infintration Rate of in Place Pervious Concrete. [S.I.]: ASTM International, West Conshohocken, PA, 2009.

GUIMARÃES, Rosangela Maria Amorim Benevides. SEGREGAÇÃO E INUNDAÇÃO URBANA: APONTAMENTOS SOBRE O PAPEL ÉTICO-POLÍTICO DO SERVIÇO SOCIAL JUNTO AOS AFETADOS. REINPEC-Revista Interdisciplinar Pensamento Científico, v. $4, \quad$ n. $\quad 2, \quad 2018 . \quad$ Disponível em: <http://reinpeconline.com.br/index.php/reinpec/article/view/197>. Acesso em: 16/07/2021. 
MARCHIONI, Mariana; SILVA, Cláudio Oliveira. Pavimento intertravado permeável - melhores práticas. ABCP - Associação Brasileira de Cimento Portland. São Paulo, 2011. Disponível em: <https://abcp.org.br/download/pavimentos-permeaveis/>. Acesso em: 16/07/2021.

OLIVEIRA, Arlan Jefferson Miguel de. Controle de inundações: causas, consequências e possíveis medidas de proteção urbana no município de Mulungu/PB. 47f. Trabalho de Conclusão de Curso (Graduação em Geografia)- Universidade Estadual da Paraíba, Guarabira, 2017. Disponível em: <http://dspace.bc.uepb.edu.br/jspui/handle/123456789/14489>. Acesso em: 16/07/2021.

ONO, Bruno Watanabe; BALBO, José Tadeu; CARGNIN, Andréia. Análise da capacidade de infiltração em pavimento permeável de bloco de concreto unidirecionalmente articulado. TRANSPORTES, v. 25, n. 3, p. 90-101, 2017. Disponível em: <https://doi.org/10.14295/transportes.v25i3.1314>. Acesso em: 16/07/2021.

Enviado: Junho, 2021.

Aprovado: Dezembro, 2021. 